\title{
UTILITARIANISM, CONSCIENCE AND ANIMALS
}

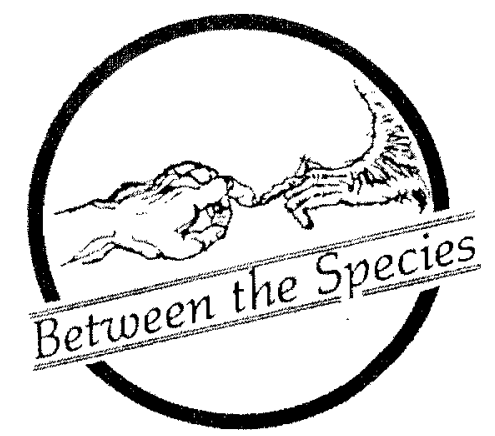

Tal Scriven

California Polytechnic State University at San Luis Obispo

Jim Harter, Animals: 1419 Copyright-Free Illustrations. New York: Dover, 1979

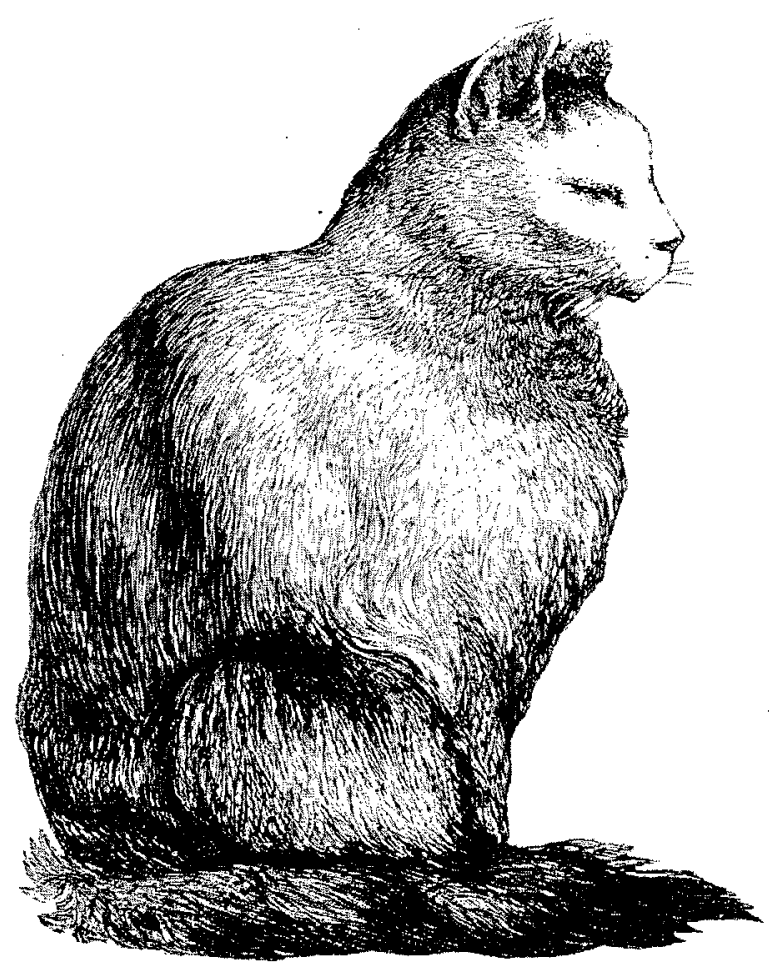

\section{Editors' Note:}

This paper and the commentary on it by Professor Barad were presented at the Pacific Division meeting of the Society for the Study of Ethics and Animals held in Portland, Oregon, March, 1988.

The current debate about the treatment of animals has broken down into the usual categories of contemporary moral debate. On one side are the deontologists like Tom Regan and, on the other, utilitarians like Peter Singer. On the face of it, it would seem that the deontologist who is intent on establishing the immorality of present modes of animal exploitation would have the tougher row to hoe. Most deontologists seem to have followed Kant's lead in denying nonhuman animals membership in the kingdom of ends. Whatever minimal status they have has generally been viewed as entirely derivative from the interests of humans who, alone among animals, have direct membership in the moral community. As a result, any attempt such as Regan's to elevate animals above the level of

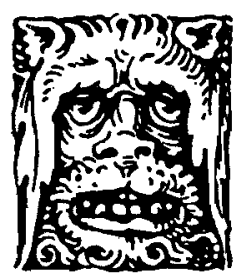

PHILOSOPHY 
mere means to human ends will entail a major readjustment of the traditional deontological conceptions of rights and duties.

On the other hand, utilitarians like Singer have tradition on their side. Since Bentham, utilitarians have recognized that animals have direct status as members in the moral community because of either their ability to feel pain or their apparent desire not to be in pain. The simple feeling of pain is enough for hedonistic utilitarians, and the presence of an interest in not being caused pain is enough for preference utilitarians. So it would appear.

What I will argue is that things are not so simple. When fully grounded in utilitarian theory, I think the issue of the status of animals (and other marginal entities like fetuses) is irresolvably problematic. For reasons I will only touch upon, things are much more problematic for the preference urilitarian than for the hedonist. But even the most straightforward hedonism will entail no clear position on the moral status of animals (and certain kinds of humans).

My aim is not simply to sow confusion. I take it as a mark of a good moral theory that it can recognize hard cases and, moreover, can explain why they are so hard. As a utilitarian, I am therefore uncomfortable with the idea that utilitarianism delivers an easy verdict on issues as profoundly confusing as the status of animals, fetuses, severely disabled humans and so on. There are other, more directly utilitarian reasons for being relieved that there is so much unavoidable confusion about things like animals and fetuses. I will return to these at the end of the paper.

The motivation for making this issue more theoretically complicated than has been usual is also founded on the inadequacy of the criteria used in simpler arguments. As for the preference utilitarianism of Singer, there are, first of all, pressing concerns about the coherence of the theory itself. 1 More immediate, however, is the problem of inferring that animals have a desire or preference not to be in pain. This inference of mental states from behavior can only be of comfort to those already convinced that animals are cognitively complicated enough to count as moral agents. To the unconvinced the inference is bound to look like so much question begging. They will simply deny that cows have anything as complicated as beliefs and desires going on in their bovine "minds." Do rats even know when they are in pain? Do chickens know anything at all?

Things are a little more promising for the hedonist. Even the most persistent human chauvinist will go so far as to admit that animals feel pain. But once again, using sentience as a criterion will not do the work the animal liberationist wants it to do. Given that they feel pain, one can still wonder how important it is to them that they not feel it. Is it important enough to override our well-articulated desires to skin, eat and experiment on them? Also, if their overall life as farm or lab animals can be made just barely to net a small amount of pleasure, would that warrant our present use of them? Moreover, would that compel us to bring more of them into our exploitive realm, since that marginal balance of pleasure over pain would not exist were it not for our desire to exploit them? Finally, would the use of painless slaughter techniques satisfy a Singer or a Salt?

It is in the responses of the animal liberationist to the last two questions that we find the inadequacy of a straightforward use of the sentience criterion. It is here also where the deontologist is given an opening to press for the inadequacy of the utilitarian defense of animals. It is not really the simple balance of pain against pleasure that matters here. It is rather our typical disregard for animals and our belief that their lives are basically less important than ours that disturbs the animal liberationist. The real problem is that they are viewed as mere means to our ends, that they have no value and no respect as ends in themselves.

I don't doubt that the sentience criterion could be given a better run for its money than I have given. But I would beg the indulgence of the defensive utilitarian until I have completed my argument.

As I see it, the issue of animals is much more directly connected to the justification of utilitarianism than it is to the application of the theory. Utilitarians from Plato (at least the Plato who wrote Protagoras) to Mill to Brandt have always thought that the Thrasymachuses of the world deserved a 
straightforward answer to their demand for a reason to be moral. It comes in three stages. The first line of argument contends that one should be moral (which for the utilitarian means, generally, that one should be benevolent) because of the threat of external sanctions. Any act of immorality is likely to catch up with you. This argument could only satisfy the hopelessly dull, however. Any of us who have ever done something wrong and gotten away with it (which is most of us) have considerable grounds for rejecting the argument.

The next line of defense is to argue that one should be moral because of the threat of internal sanctions, because of guilt brought on by conscience. But why worry about guilt? Why have a conscience? After all, if I am an egoist waiting for a reason to be moral, my conscience ought to make me feel guilty about not being selfish.

This brings us to the third stage of the response. Conscience is not the creation of the individual. Nor for almost all utilitanans, is it innate (although the sociobiologists might someday convince us that it is). Conscience is the result of programming. And like all effects of behavioral programming, it can be extinguished. So why fear the deterioration of conscience, especially when it keeps getting in the way of my self-interest? Because as a matter of pure fact, in an advanced civilization interests are so intermingled, so interdependent, that anyone who loses a benevolent conscience and develops a narrowly egoistic "course of life" (as Mill called it) will surely pay for it. The vices of naive egoism have an addictive quality about them, and once the fragile barrier of conscience dissolves, nothing will save us from the tyranny of excess. There is a price to be paid for not generalizing concern about one's own interests into concern for the interests of other beings who are more or less like oneself and who have interests that are more or less synonymous with various of one's own interests.

So it is conscience that saves us from ourselves and from each other. But how does it save animals from us? It saves them because of the variability of the conditions under which it arises. Conscience is formed as an individual passes from teacher to teacher in a society of moral teachers who find it advantageous to impose concern for others (the teachers) on the individual. As one encounters teachers with increasingly different characteristics, the range of things one ought to be concerned about grows. But the development of conscience is complicated, emotively and logically. At the emotive level the generalization of concern is constrained by the fact that as beings become less like us, the rational egoistic grounds for concern about them become weaker. $\mathrm{My}$ interests are highly interdependent with those of my family and colleagues. This common sense interdependence lessens as I consider the importance to me of Americans in general, Ethiopians, fetuses, mammals, birds and so on. In fact, as beings become less like me, I will find not only that my interests are not synonymous with theirs but incompatible with theirs. At the outer limits concern about beings like fetuses and chickens might seem to be productive of nothing but needless guilt, which must be of concern to the utilitarian contemplating the optimal arrangement of institutions and laws.

At the logical level the hitch comes in the analysis of criteria under which beings count or don't count as "enough like me" to warrant my respect and benevolence. No criterion is going satisfactorily to include everything any given individual has come to accept as "enough like me" and exclude everything that is not "enough like me" to count. Criteria that include mammals but exclude human fetuses will be hard for vegetarian feminists to defend. Criteria that include fetuses but exclude chimps will be hard for meateating antiabortionists to defend. Criteria that include redwoods but exclude pumpkins will cause trouble for vegetarians who are also very radical environmentalists.

This brings us to my basic point: it is, I think, a very good thing that we are unable to settle upon any widely accepted criterion that would nicely exclude animals or fetuses from the moral community. The broad acceptance of any such criterion would, as animal liberationists and antiabortionists are quick to point out, lead to the exclusion of many humans from the moral community. Moreover, the implausibility of any rigid criterion is great fodder for racists, sexists and fascists who will argue that the utilitarian notion of equal consideration of human interests is a myth with no logical support. The general habit of dreaming up 
membership qualifications for the moral community is from a utilitarian and from a purely human perspective very dangerous. It is fortunate indeed that we are totally confused about how seriously the suffering of animals and fetuses should be taken. Should we be as concerned about fetuses and cows as we are about our pets or even our children? Or should we be as unconcerned about them as we are about creatures as dissimilar to us as ants and snail darters?

However we answer these questions, I would contend that our answer really will not be derived from any rationally grounded criterion. Rather, it will be grounded in the intricacies of conscience formation, in millions of "intuitions" turned out by millions of behavioral histories. These kinds of issues bring us to the emotive edge of applied ethics. Issues like euthanasia for competent adults, regulation of business, and taxation policy are much nearer to the cognitive surface. In these cases agreement with the basic tenets of classical utilitarianism will leave mostly factual issues to argue about.

As far as any social policy about the status of animals or fetuses is concerned, however, there is reason to believe that the function of moral philosophy is primarily critical and destructive. It should seek, for good utilitarian reasons, to muddy any clear water others claim to find. There are clear utilitarian costs to humans if we manage to muster agreement that animals and fetuses count as importantly as people, but there are also considerable costs to humans in establishing some clear criterion that excludes the lives of animals and fetuses from being morally important.

Thus, I think the most prudent course for human social policy is the current status quo. Individuals should be allowed to follow their own consciences on the matters of abortion, vegetarianism and animal experimentation. But they should do so in the knowledge that the spectacles of truckloads of fetuses, marginally profitable barbarity to livestock and frivolous animal experimentation will not be without consequences for social policy. Such spectacles are bound to affect the sensibilities of quite moderate people who have not had to develop the numbness to suffering and death of the physician, butcher or vivisector.

On the bottom line I have come to a position more or less equivalent to one recently advocated by Jan Narveson. My reasons for arriving at this bottom line are quite different from his, however. Arguing from a contractarian perspective, Narveson nails the issue down to the following Hobbesian consideration:

The fact, for instance, that if I were a pig, I would want pigs...to be treated well is of no interest, ...the pig himself has no rational clout. $\mathrm{He}$ is not able to address himself to the question of what he can do to make life difficult for us if we don't cater to his needs, or of how much better he could make it for us if we do. If we want something out of the pig, and treating the pig well is necessary for getting it, then we shall have reason to treat him well. If we don't, however, or it isn't, then why should we go to the trouble?

The problems with this kind of prisoner's dilemma ethic are well-known and have been since Braithewaite's Game Theory as a Tool for the Moral Philosopher was reviewed in the 1950 's. ${ }^{3}$ If threat advantage is a necessary condition for moral consideration, then one wonders about the consequences of substituting "Ethiopian" for "pig" in the above argument. If, on the other hand, it is some kind of sufficient condition, then do grizzlies have more status than Ethiopians?

At any rate, the point I have tried to make is that the welfare of animals is of concern to humans. And although confusion about their status may be viewed as only instrumentally valuable in the development of social policy, questions about their intrinsic value cannot be pushed aside as Narveson or anyone else may want to do. But no matter how hard we try, the issue of how much we ought to be concerned about the suffering of animals is - and ought to be impossible to settle on rational grounds.

\section{Notes}

\footnotetext{
1See my "Plato's Democratic Man and the Implausibility of Preference Utilitarianism," forthcoming in. Theory and Decision. p. 42 .

2"On a Case for Animals' Rights" Monist, 70, Jan. 87 (31-49)

${ }^{3}$ Cambridge University Press (1955). For a discussion see R. D. Luce and $H$. Raiffa, Games and Decisions. (New York: Wiley and Sons, 1957), pp. 145-150.
} 